\title{
A Micro-Comb Test System for In Situ Investigation of Infiltration and Crystallization Processes
}

\author{
Dominik Gruber ${ }^{\dagger}$, Stefan L. P. Wolf ${ }^{\dagger}$, Andra-Lisa M. Hoyt, Julian P. Konsek \\ and Helmut Cölfen * \\ Department of Chemistry, Physical Chemistry, University of Konstanz, Universitätsstraße 10, 78457 Konstanz, \\ Germany; dominik.gruber@uni-konstanz.de (D.G.); stefan.3.wolf@uni-konstanz.de (S.L.P.W.); \\ andra-lisa.hoyt@uni-konstanz.de (A.-L.M.H.); Julian.Konsek@uni-konstanz.de (J.P.K.) \\ * Correspondence: Helmut.Coelfen@uni-konstanz.de; Tel.: +49-7531-88-4063 \\ t These authors contributed equally to this work.
}

Received: 31 August 2017; Accepted: 3 October 2017; Published: 6 October 2017

\begin{abstract}
The investigation of mineralization and demineralization processes is important for the understanding of many phenomena in daily life. Many crystalline materials are exposed to decay processes, resulting in lesions, cracks, and cavities. Historical artifacts, for example, often composed of calcium carbonate $\left(\mathrm{CaCO}_{3}\right)$, are damaged by exposure to acid rain or temperature cycles. Another example for lesions in a crystalline material is dental caries, which lead to the loss of dental hard tissue, mainly composed of hydroxyapatite (HAp). The filling of such cavities and lesions, to avoid further mineral loss and enable or support the remineralization, is a major effort in both areas. Nevertheless, the investigation of the filling process of these materials into the cavities is difficult due to the non-transparency and crystallinity of the concerned materials. In order to address this problem, we present a transparent, inexpensive, and reusable test system for the investigation of infiltration and crystallization processes in situ, being able to deliver datasets that could potentially be used for quantitative evaluation of the infiltration process. This was achieved using a UV-lithography-based micro-comb test system (MCTS), combined with self-assembled monolayers (SAMs) to mimic the surface tension/wettability of different materials, like marble, sandstone, or human enamel. Moreover, the potential of this test system is illustrated by infiltration of $\mathrm{a} \mathrm{CaCO}_{3}$ crystallization solution and a hydroxyapatite precursor (HApP) into the MCTS.
\end{abstract}

Keywords: porous mineral; infiltration analysis; self-assembled monolayer; surface modification; calcium phosphate; calcium carbonate; dental hard tissue; artifact restoration; remineralization; biomaterials

\section{Introduction}

Crystallization processes in confined environments are essential for a wide range of fields, ranging from scaling in pipelines, to biomineralization, to the construction industry [1-12]. All of these processes are characterized by a hindered ion diffusion, locally higher supersaturation, and often heterogeneous crystallization. Therefore, crystallization is observed in areas where nucleation is unexpected under the applied conditions, like acute steps or pockets [13-15]. However, it is also commonly observed that crystallization is significantly slowed down in confinement or even completely inhibited [2,11,15-19].

In the case of concrete, calcium oxide links the already crystallized silicon dioxide to form a brittle but very hard material, like calcium silicate hydrate in cements [9]. In the early centuries such high-end materials were not available for architecture. Therefore, naturally-abundant materials like marble or sandstone were used to build monuments that are still impressive nowadays, like the Pantheon in Rome, the Acropolis in Athens, or the Cologne Cathedral. 
Sandstones, like Pietra Serena (PS), are composed of a mixture of oxides and carbonates and are characterized by a relatively high porosity $[20,21]$. In addition, they are relatively soft and easy to handle, which is among the reasons why this material was often used in architecture. In comparison, marbles are materials containing varying degrees of carbonates, depending on the quarrying area, especially of calcium [22]. Carrara marble (CM) represents a class of rock with a carbonate content of over $80 \%$ and a generally lower porosity [20]. Due to the exquisite white color, CM was often used for statues and architecture, as well [22]. Over the centuries of their existence, historical monuments and artworks are exposed to many decay processes [22]. The porosity of the stones enables the infiltration of water, which can result in mechanical stress and, finally, in damage of the structural integrity of the stones due to thermal cycles and crystallization processes inside the pores. This also shows how important a better understanding of crystallization in confined environments is [23]. Additionally, chemical reactions - e.g., caused by acid rain — can lead to cracks and cavities, for example, due to the dissolution of $\mathrm{CaCO}_{3}$. To preserve historical artifacts by preventing further damage and restoring the integrity, several restoration formulations have been developed [24-26].

Similar problems related to acid-induced decay processes and subsequent mineral loss are a major challenge in dentistry-called dental caries. It is the most common chronic disease around the world affecting more than $95 \%$ of concerned adults $[27,28]$. Caries result from bacteria, which form a biofilm on the teeth. These bacteria metabolize carbohydrates and produce acids as by-products [29]. The acidic metabolites demineralize the dental hard tissues-enamel and dentin-mainly composed of hydroxyapatite (HAp), resulting in the formation of lesions in the range of nanometers to hundreds of microns [30-32]. Due to the enormous number of diseased individuals, several different treatments for refilling the cavities have been established. The developed filling materials range from cements [33-35] over (nano)ceramics [36,37] to peptide-amorphous calcium phosphate composites $[38,39]$. Nevertheless, the mode of action of many fillings is not completely understood.

The investigation of the infiltration behavior of new filling materials in dental lesions, as well as in pores and cracks in historical artifacts, is a great challenge. Furthermore, the investigation of the underlying mechanism of the interactions with the substrates (stones and teeth) is crucial for the development and validation of the filling methods and materials. In both cases, the production of suitable tests systems (TSs) is complex and time consuming. The stone samples need to be aged artificially to create controlled and reproducible cavities and damage. This is usually achieved by multiple cycles of thermal shock or hot-cold cycling, purposeful infiltration of soluble salts, or treatment with acids [40-42]. For the dental TSs, the usage of artificial tooth lesions, made of bovine or human teeth, is the state of the art $[39,43,44]$. Therefore, the teeth need to be embedded in a polymer matrix, polished afterwards and etched with acids $[39,44,45]$. Both tooth and stone TSs, need to be replaced after each experiment, resulting in a high consumption of the TSs. Apart from the sophisticated preparation of the TSs, it is difficult to obtain an insight into the lesions due to the crystallinity of the TSs and non-transparency to visible light. The investigation of infiltration depth and crystallization processes of fillers with light microscopy or scattering techniques is hindered.

In this paper, we present the fabrication of a UV-lithography-based, transparent, inexpensive, and reusable micro-comb test system (MCTS) for the investigation of infiltration and crystallization processes in situ by using common methods, like optical light microscopy (LM). The lesions of the MCTSs were varied from $10 \mu \mathrm{m}$ to $100 \mu \mathrm{m}$ in width. In addition, the surface tension/wetting properties of PS and CM were imitated, as well as human enamel, by using a mixture of different thiols in self-assembled monolayers (SAMs). Furthermore, we investigated the infiltration and crystallization of $\mathrm{CaCO}_{3}$ and HAp in the MCTSs using an infiltration setup. 


\section{Materials and Methods}

\subsection{Materials}

Poly(acrylic acid) sodium salt (PAA, $\mathrm{M}_{\mathrm{w}}=8000 \mathrm{~g} / \mathrm{mol}, 45 \mathrm{wt} \%$ in water, $\mathrm{M}_{\mathrm{w}}=15,000 \mathrm{~g} / \mathrm{mol}$, $35 \mathrm{wt} \%$ in water), calcium chloride dihydrate $\left(\mathrm{CaCl}_{2} \cdot 2 \mathrm{H}_{2} \mathrm{O}, \geq 99 \%\right), 2$-Amino-2-(hydroxylmethyl)-1,3propanediol (Tris, $\geq 99,9 \%$ ), 2-Propanol (iPrOH, p.a.), and 11-mercapto-1-undecanol (MUO, 97\%) were purchased from Sigma Aldrich (Taufkirchen, Germany). Disodium hydrogen phosphate $\left(\mathrm{Na}_{2} \mathrm{HPO}_{4}\right.$, $\geq 98 \%$ ) and ethanol (EtOH, p.a.) were purchased from Carl Roth (Karlsruhe, Germany). Potassium chloride $(\mathrm{KCl}, 99.5 \%)$, sodium hydrogen carbonate $\left(\mathrm{NaHCO}_{3}, \mathrm{p}\right.$. a. $)$, and sodium hydroxide solution $(\mathrm{NaOH}, 0.1 \mathrm{~N})$ were obtained from Merck Chemicals (Darmstadt, Germany). 1-Dodecanethiol (DDT, $\geq 98 \%$ ) and poly(acrylic acid) (PAA, $\mathrm{M}_{\mathrm{w}}=2000 \mathrm{~g} / \mathrm{mol}, 63 \mathrm{wt} \%$ in water) were purchased from Acros Organics (Geel, Belgium). The photoresist SU-8 3050 and photo developer mr-Dev 600 were purchased from Micro Resist Technology (Berlin, Germany). All chemicals were used without further purification. All experiments were carried out using double-deionized water (18.2 M $\Omega$ ) using a Milli-Q Direct 8 machine from Merck Millipore (Darmstadt, Germany).

\subsection{UV-Lithopgraphy of the Micro-Comb Test System (MCTS)}

For the production of the MCTSs, $1 \mathrm{~mL}$ of photoresist was spin-coated onto a $2.5 \times 2.5 \mathrm{~cm}^{2}$ glass slide with a defined coating program $(500 \mathrm{rpm}$ for $10 \mathrm{~s}$ with a ramp-up of $100 \mathrm{rpm} / \mathrm{s}$ and then $30 \mathrm{~s}$ at $1400 \mathrm{rpm}$ with a ramp-up of $300 \mathrm{rpm} / \mathrm{s}$ ). The coated layer was heated for $45 \mathrm{~min}$ at $95{ }^{\circ} \mathrm{C}$, covered with the lithography mask and exposed to UV-light $(\lambda=365 \mathrm{~nm})$ for $7 \mathrm{~min}$. Afterwards, the substrate was heated for $1 \mathrm{~min}$ at $65^{\circ} \mathrm{C}$ and $5 \mathrm{~min}$ at $95^{\circ} \mathrm{C}$. The resin was placed in the photo developer and was ultrasonicated for $15 \mathrm{~min}$. The structured resin was lifted off the glass, washed with $\mathrm{PrOH}$ and dried with a nitrogen stream. To receive a straight infiltration border at the open end of the channels, the comb-teeth were cut to the same size using a microtome.

\subsection{Surface Modification Using Self-Assembled Monolayers (SAMs)}

All substrates (glass platelets and MCTSs) were rinsed with water and $\mathrm{PrOH}$, then coated with $5 \mathrm{~nm}$ chromium to facilitate the adhesion of the $20 \mathrm{~nm}$ gold layer. Both layers were deposited by thermal evaporation. The substrates were modified with freshly-prepared thiol solutions or mixtures of DDT and MUO (5 mM in EtOH each) by incubating for $12 \mathrm{~h}$ (Figure 1D). After washing the samples with $\mathrm{iPrOH}$ and drying with a nitrogen stream, contact angles where measured statically. A drop of $10 \mu \mathrm{L}$ water was manually deposited on the surface. Drop deposition and spreading was recorded via video. For analysis, the video was replayed and stopped $5 \mathrm{~s}$ after drop deposition to measure the contact angle $\theta$. The measurements where repeated 5 times to calculate the average and the standard deviation.

\subsection{Synthesis and Infiltration of the $\mathrm{CaCO}_{3}$ Crystallization Solution}

The solution was adapted from Wolf et al. [46]. For the $\mathrm{CaCO}_{3}$ crystallization solution, a stock solution of $9.9 \mathrm{mM} \mathrm{CaCl}$ and $10 \mu \mathrm{g} / \mathrm{mL}$ PAA $\left(\mathrm{M}_{\mathrm{w}}=2000 \mathrm{~g} / \mathrm{mol}\right)$ was prepared and the $\mathrm{pH}$ was adjusted to 9.1. $1.04 \mathrm{~mL} \mathrm{NaHCO} 3(100 \mathrm{mM})$ were added dropwise to $10 \mathrm{~mL}$ of the stock solution while stirring, and the $\mathrm{pH}$ was adjusted to 9. The solution became slightly turbid. The freshly prepared $\mathrm{CaCO}_{3}$ crystallization solution was infiltrated into the MCTS using the infiltration setup (Figure 1C).

\subsection{Synthesis and Mineralization of the Hydroxyapatite Precursor (HApP)}

The HApP was synthesized as described by Wang et al. [47]. In summary, $10 \mathrm{~mL}$ of a $\mathrm{CaCl}_{2}$ solution $(40 \mathrm{mM})$ were added slowly to $10 \mathrm{~mL}$ of a stirred PAA-sodium salt solution $(400 \mathrm{mg} / \mathrm{L})$. Afterwards, $10 \mathrm{~mL} \mathrm{Na} \mathrm{HPO}_{4}$-solution $(20 \mathrm{mM})$ was added to the turbid solution. The mixture was stirred for $10 \mathrm{~min}$, then centrifuged for $10 \mathrm{~min}$ at $1000 \mathrm{rpm}$ and washed with $30 \mathrm{~mL}$ water. 
The washing steps were repeated three times in total. Prior to infiltration, the HApP was concentrated by centrifugation for $10 \mathrm{~min}$ at $1000 \mathrm{rpm}$.

The freshly prepared HApP was used for infiltration experiments. The infiltrated MCTS were incubated in a remineralization solution $\left(1.5 \mathrm{mM} \mathrm{CaCl}_{2}, 0.9 \mathrm{mM} \mathrm{Na}_{2} \mathrm{HPO}_{4}, 130 \mathrm{mM} \mathrm{KCl}, 60 \mathrm{mM}\right.$ Tris with different $\mathrm{pH}$ values, ranging from 7.4 to 11) as described by Kirkham et al. [45] for seven days. Prior to the investigation of the results using LM, PLM, SEM, and PXRD, the top glass platelet was removed, the sample was carefully cleaned with water to eliminate soluble salts, and air-dried.

\subsection{Instruments}

The substrates were spin-coated using an OPTIcoat SB20+ from SSE (ATM Group, Degotec GmbH, Singen, Germany). The lithography mask was manufactured by Compugraphics Jena GmbH (Jena, Germany). The UV-lithography was performed using a MJB3 Mask Aligner from Süss MicroTec AG (Garching, Germany) with a mercury vapor lamp. A Leica EMFC6 microtome (Wetzlar, Germany) was used for the fine cutting of the MCTS. For the thermal evaporation of $\mathrm{Cr}$ and $\mathrm{Au}$, a Tectra Minicoater (Frankfurt a. M., Germany) was used. A Zeiss Stemi 2000-C (Jena, Germany) stereomicroscope with an AVC 535 Color CCD camera was used for contact angle measurements. All (polarized-)light microscopy ((P)LM) images were recorded on a Zeiss Imager M2Mm with a Zeiss AxioCam MRc5. Scanning electron microscopy (SEM) and energy-dispersive X-ray spectroscopy (EDX) were performed on a Hitachi TM 3000 instrument (Tokyo, Japan) coupled with a Quantax EDX detector from Bruker (Berlin, Germany). Powder X-ray diffraction (PXRD) measurements were performed with a D8 Discover X-Ray diffractometer $(\mathrm{Cu}, \mathrm{K} \alpha)$ with a VANTEC-500 detector from Bruker (Karlsruhe, Germany).

\section{Results and Discussion}

\subsection{The Micro-Comb Test System (MCTS) and the Surface Modification with Self-Assembled Monolayers (SAMs)}

The investigation of the infiltration process is essential for the development of filling materials for dental applications and other restorative products as well. To facilitate this, a UV-lithography-based micro-comb test system (MCTS) was designed. The MCTSs are inexpensive, reusable, and transparent to visible light. The channels between the comb-teeth are varied from 10 to $100 \mu \mathrm{m}$ in width and up to $10 \mathrm{~mm}$ in length to mimic the pores and lesions in the real systems. A gradient in the channel width was designed, as well, to investigate the influence of the lesion width on the infiltration behavior (Figure 1A). To ensure a uniform infiltration, the comb-teeth were cut to the same length using microtome cutting. It should be mentioned that this step is rather delicate due to the brittle epoxy resin and the high shearing forces perpendicular to the comb-teeth during the microtome cutting. It is desirable for the infiltration and mineralization experiments to produce MCTS with just a few microns in thickness to mime the confinement in real systems. The MCTS is placed into the newly-developed infiltration setup, shown in Figure 1B. To avoid spilling of the infiltration solution, the MCTS is closed and sealed with an upper and a bottom glass platelet ((2) and (6) in Figure 1B). This sandwich-like system is covered by a metal frame (1), which is fixed in place with four screws (4) to distribute the pressure evenly and seal the system completely. In the acrylic glass base plate (8), a reservoir (7) is provided for the infiltration solution in front of the MCTS channel entrance. The reservoir can be filled via the inlet (3) in the metal frame. Another advantage is that the reservoir enables an equal infiltration of all channels in the MCTS. The whole infiltration setup is transparent for visible light, which allows the analysis with LM and PLM in situ and in real time.

To determine the infiltration behavior of filling materials, the wettability of the substrate with the filler is a crucial factor. The MCTS is made of an epoxy resin, which results in different wetting properties than the highly hydrophilic calcium carbonate or phosphate surfaces. To overcome this problem, we modified the surface of the MCTSs as well as the upper and bottom glass platelets with self-assembled monolayers (SAMs). The formation of SAMs on gold surfaces using thiols is a well 
understood and robust system [48,49]. The structure of a SAM on a gold surface is shown in Figure 1C. The thiol groups bind with high affinity to the gold surface and stabilize the surface atoms [49]. The organic spacer, in this case a $\mathrm{C}_{11}$-alkane chain, provides a defined thickness of the monolayer and acts as a physical protection barrier for the surface. The terminal functional groups determine the surface properties like the wettability of the SAM-covered surface. By using a mixture of different functionalized thiols, like 11-mercapto-1-undecanol (MUO) and 1-dodecanethiol (DDT), mixed SAMs are available, resulting in an average of the surface properties (Figure 1C, bottom). The wettability of a surface with a liquid phase correlates to the contact angle $\theta$ [50]. The usage of different mixtures of MUO and DDT for the formation of SAMs results in different contact angles, as shown in Figure 1D. A SAM made of pure MUO yields a highly hydrophilic surface $\left(\theta=26^{\circ} \pm 3^{\circ}\right)$, which is nearly similar to the wettability of PS $\left(\theta=33^{\circ} \pm 2^{\circ}\right)$ [40], whereas pure DDT results in a SAM with a hydrophobic surface $\left(\theta=104^{\circ} \pm 2^{\circ}\right)$. The mixture of different volume ratios of MUO and DDT leads to a variety of contact angles between $26^{\circ}$ and $104^{\circ}$. A ratio of 70:30 $(v / v)$ of MUO:DDT results in a SAM with an contact angle of $\theta=58^{\circ} \pm 3^{\circ}$ which perfectly matches the wettability of healthy human enamel $\left(57^{\circ}<\theta<60^{\circ}\right)[50,51]$ and is also in good accordance with $\mathrm{CM}\left(\theta=50^{\circ} \pm 4^{\circ}\right)$ [40]. Prior to infiltration experiments all MCTSs and glass platelets are functionalized with SAMs to yield a material with similar wettability to the material to be imitated.
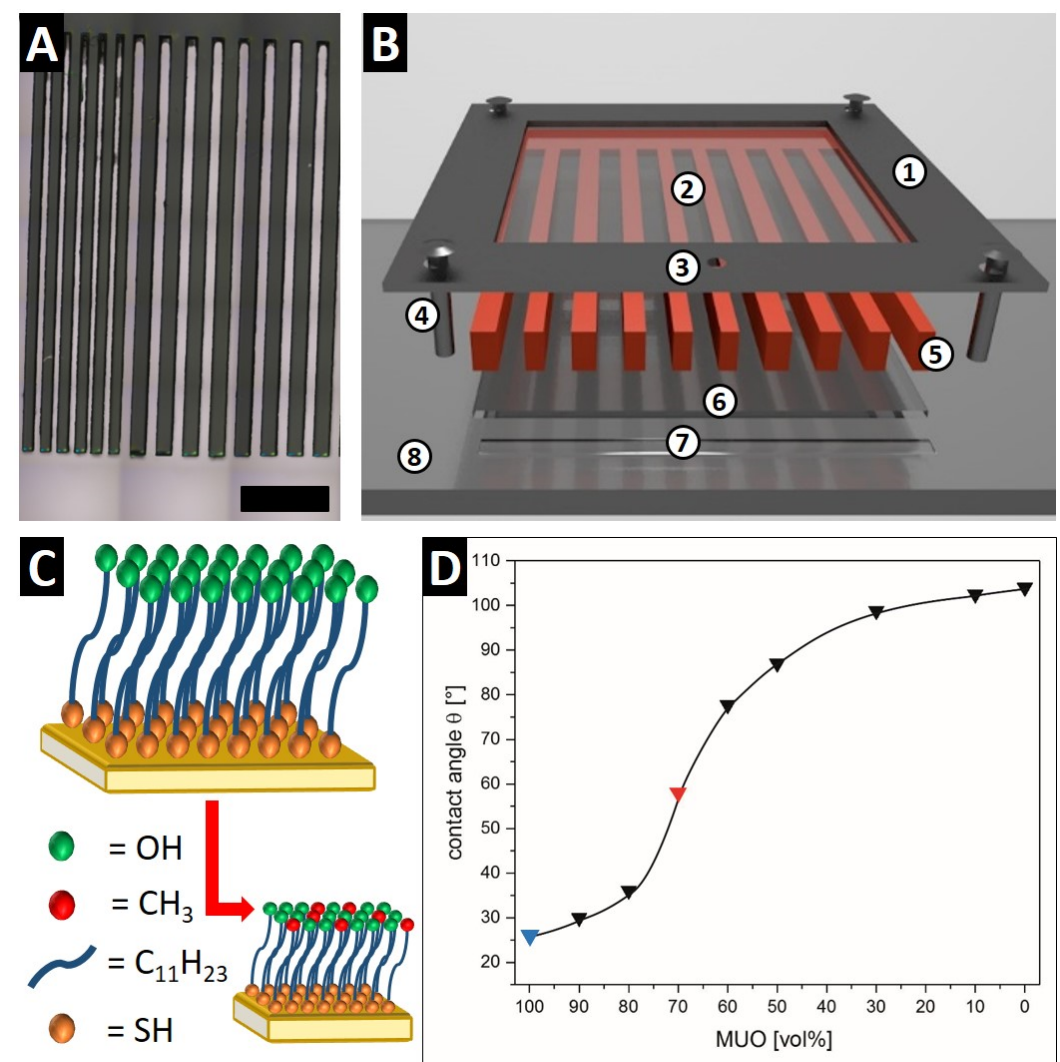

Figure 1. (A) LM image of a micro-comb test system (MCTS) (scale $1000 \mu \mathrm{m}$ ). (B) Schematic drawing of the infiltration setup with all compounds numbered: (1) metal frame; (2) top glass platelet; (3) inlet for solutions; (4) screws; (5) MCTS; (6) bottom glass platelet; (7) reservoir for infiltration solution; and (8) acrylic glass base plate. (C) Schematic image of a homogenous, hydroxyl-terminated self-assembled monolayer (SAM) on a gold surface (top) and a mixed SAM with 70\% hydroxyl-terminated and 30\% methyl-terminated thiols (bottom). (D) Contact angle measurements of SAM-modified, gold-coated substrates with different mixtures of MUO and DDT. The blue triangle symbolizes the pure MUO-SAM to mimic the wettability of PS. The red triangle symbolizes the thiol mixture 70/30 $(v / v)$ to mimic the wettability of enamel and CM. The black line is the expected guideline for other mixtures. 


\subsection{Infiltration of a MUO-Modified MCTS with a $\mathrm{CaCO}_{3}$ Crystallization Solution}

To validate the newly-designed MCTS, the micro-comb and the glass platelets were modified, using a MUO-SAM $\left(\theta=26^{\circ} \pm 3^{\circ}\right)$ to mimic a realistic situation of a damaged PS sample $\left(\theta=33^{\circ} \pm 2^{\circ}\right)$, and infiltrated with a $\mathrm{CaCO}_{3}$ crystallization solution. For the infiltration experiments, the newly-developed infiltration setup was used (Figure 1B), which enables the investigation in situ using LM. Figure $2 \mathrm{~A}$ shows a $\mathrm{LM}$ image where small $\mathrm{CaCO}_{3}$ particles are observable, which are transported into the channels by capillary forces after the crystallization solution was added to the dry comb channel system. The particles accumulate at the liquid-air boundary and form little $\mathrm{CaCO}_{3}$ islands (Figure 2A, red circle) although the liquid meniscus is not concave as expected for aqueous solutions in a hydrophilic capillary, which indicates perturbations in our present system. The particles are also present as non-crystalline agglomerations on the channel walls (Figure 2A, blue square) suggesting that our present test system is not yet perfectly tight due to the brittle nature of the photo resist used to manufacture the comb system clamped in between the two glass plates. However, the PLM image of the same area at the same time in Figure 2B proves the crystallinity of the $\mathrm{CaCO}_{3}$ particles as they show birefringence. Figure 2C,D are an overview LM (Figure 2C) and PLM (Figure 2D) image of the dried sample. These images show again the infiltrated, crystalline $\mathrm{CaCO}_{3}$ particle islands inside the channels. The channels of the MCTS are not completely filled due to the low mineral content of the crystallization solution and just one application cycle. To increase the mineral content in the channels, either the mineral content in the precursor solution needs to be increased or a multiple infiltration process should be applied. A second strategy would be the decreasing of the channel size and volume. By optimizing the MCTS, more complex systems, like multi-component fillers, will be infiltrated. Nevertheless, the potential and the operating principle of the modified MCTS, combined with an infiltration setup, is demonstrated descriptively.

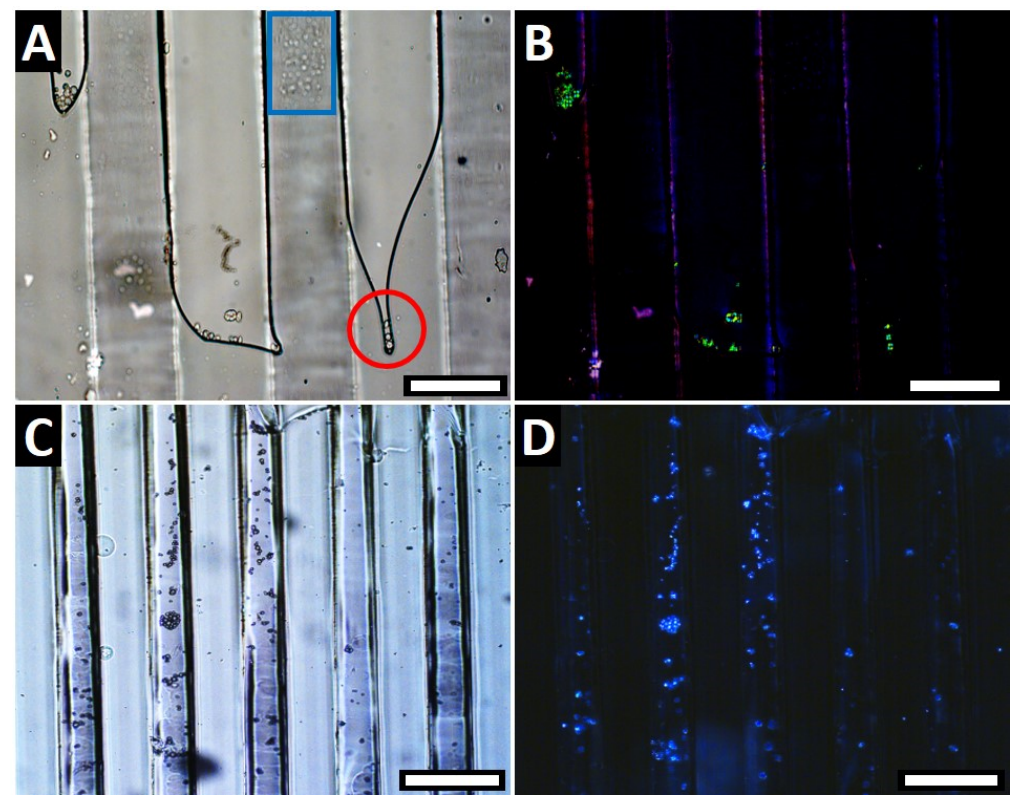

Figure 2. (A) In situ $\mathrm{LM}$ image during the infiltration of the $\mathrm{CaCO}_{3}$ crystallization solution in a MUO-modified MCTS shows small $\mathrm{CaCO}_{3}$ particles at the liquid-air boundary. The red circle highlights the resulting $\mathrm{CaCO}_{3}$ islands and the blue square indicates non-crystalline aggregates on the channel walls (scale $50 \mu \mathrm{m}$ ); (B) PLM image of the area of (A) shows the crystallinity of the $\mathrm{CaCO}_{3}$ particles in green (scale $50 \mu \mathrm{m}$ ); (C) LM image after drying in air shows the $\mathrm{CaCO}_{3}$ particles inside the channels (scale $100 \mu \mathrm{m}$ ); and (D) PLM image of the area of (C) indicates the crystallinity of the particles in the channel system by their birefringence (scale $100 \mu \mathrm{m}$ ). 


\subsection{Infiltration and Crystallization of a Hydroxyapatite Precursor (HApP)}

Dental caries was described as a second important system often affected by acid-caused mineral loss. The demineralization of dental hard tissue starts at the outer enamel layer, which is mainly composed of HAp. To mimic the surface wettability of human enamel, the MCTS and the glass platelets were modified using a thiol mixture of MUO and DDT in a 70:30 $(v / v)$ ratio (Figure 1D, red triangle). To simulate real conditions, a hydroxyapatite precursor (HApP) was synthesized and used as a potential filling material. The synthesis of the HApP was described by Wang et al. [47]. We modified the synthesis by utilizing higher molecular weights of PAA $\left(\mathrm{M}_{\mathrm{W}}=8000 \mathrm{~g} / \mathrm{mol}\right.$ and $15,000 \mathrm{~g} / \mathrm{mol}$ ) to increase the complexation kinetics of the PAA [52]. The freshly-prepared HApP was infiltrated into a MCTS with a channel width of $50 \mu \mathrm{m}$ using the infiltration setup shown in Figure 1B. The infiltrated MCTS was stored in a remineralization solution for seven days [45]. The LM image of an infiltrated MCTS shows the almost completely filled channels (dark areas in Figure 3A). The PLM image (Figure $3 \mathrm{~B}$ ) of the same area proves the crystallinity of the calcium phosphate $(\mathrm{CaP})$ filling material. The SEM image in Figure 3C shows the successful infiltration and filling of several channels with a depth of at least $500 \mu \mathrm{m}$ - the same dimension as deep human enamel lesions. The filling mineral has an unordered structure, made up of small particles, which fused together partially (Figure 3D). The PXRD of the mineralized HApP after incubation for seven days in the remineralization solution at pH 7.4 displays the crystallization to HAp (Figure 4). The broad reflexes indicate the presence of nano-crystalline hydroxyapatite, which was further confirmed by the calculation of the crystallite size of $26.3 \mathrm{~nm}$ utilizing the Scherrer equation $[53,54]$.

At the moment the system is limited to small lesions and cavities due to the straightforward synthesis procedure, the used photo resin and the spin coating program In the future we aim to increase the diversity of the MCTS and the precursor solutions as well. Furthermore, we want to adapt the system for more complex systems, like a mixture of fillers.
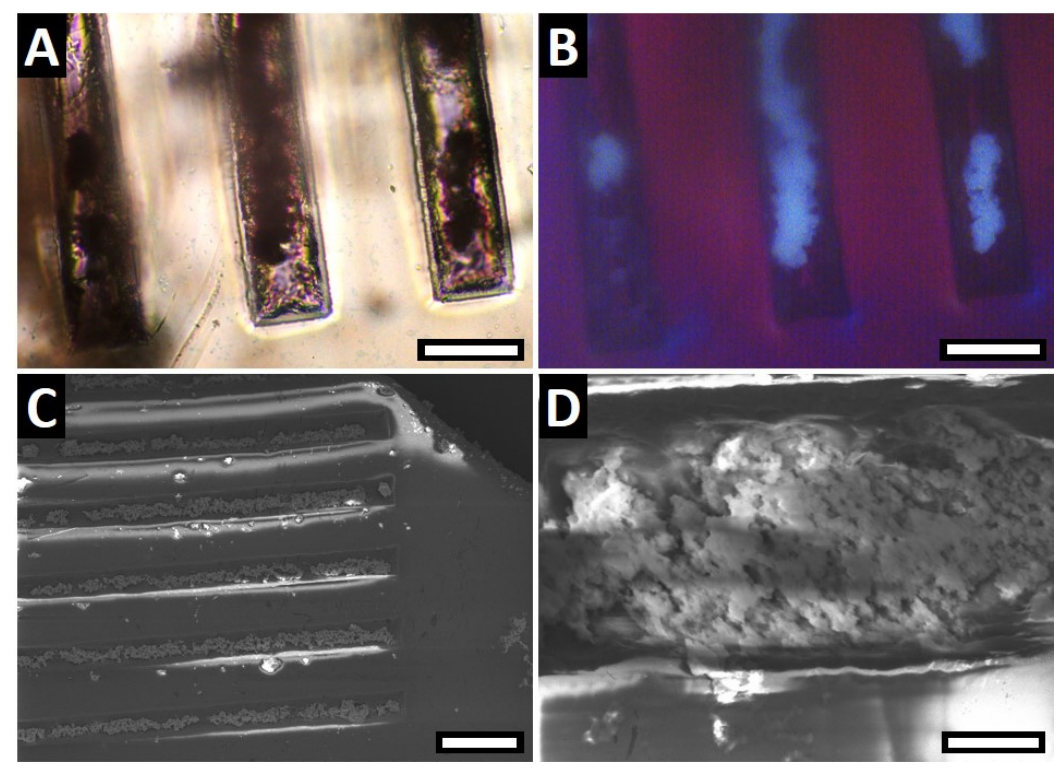

Figure 3. (A) LM image of an HApP-infiltrated MCTS, after an incubation time of seven days in the remineralization solution showing CaP-filled channels (dark area, scale $50 \mu \mathrm{m}$ ); (B) PLM image of (A) shows the crystallinity of the CaP-filling material (blue) in the channels (scale $50 \mu \mathrm{m}$ ); (C) SEM overview image of several CaP-filled MCTS channels (scale $100 \mu \mathrm{m}$ ); and (D) SEM image shows the partially fused $\mathrm{CaP}$ particles in one channel (scale $10 \mu \mathrm{m}$ ). 


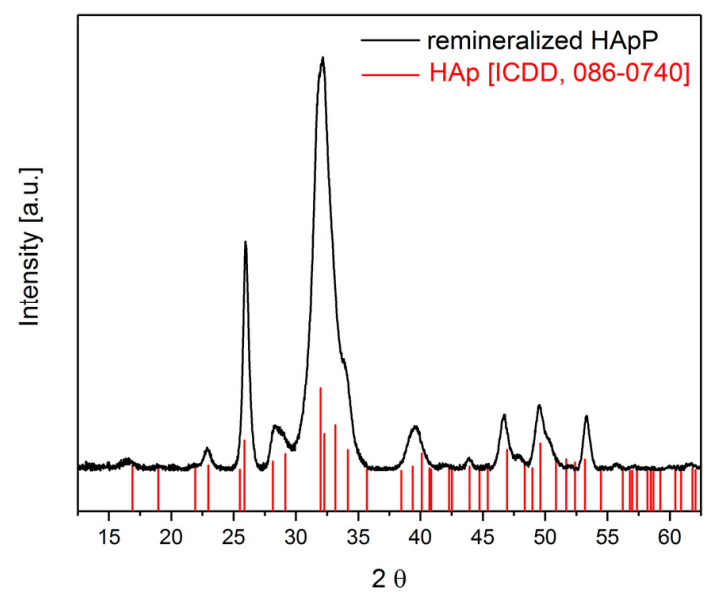

Figure 4. PXRD pattern of a crystallized HApP after incubation in the remineralization solution for seven days ( $\mathrm{pH} 7.4)$.

\section{Conclusions}

We have developed a new micro-comb test system (MCTS) for the investigation of the infiltration and crystallization behavior of filling materials for any kind of porous systems in situ. The MCTSs are inexpensive and reusable and provide a very significant advantage over natural-based test systems, like artificial tooth lesions or aged stone samples, because they are transparent and the infiltration processes can, consequently, be directly observed by optical microscopy. Therefore, the MCTS is suitable to visually investigate important infiltration processes into micrometer-sized pores. By modifying the surface of the epoxy resin-based MCTS with a self-assembled monolayer (SAM) of MUO or a mixed SAM, composed of 70\% MUO and 30\% DDT $(v / v)$, we were able to mimic the wettability of Pietra Serena (PS), as well as Carrara marble (CM) and human enamel. Beyond that, all contact angles between $26^{\circ}$ and $104^{\circ}$ are available by the appropriate mixture (see Figure 1D). Moreover, we demonstrated the potential of this powerful and straightforward test system by infiltrating a $\mathrm{CaCO}_{3}$ crystallization solution and a hydroxyapatite precursor (HApP). It is possible to investigate the depth of infiltration and mineralization in situ and in real-time.

For focusing the complete filling of the MCTSs with the mineral precursors to realize a complete remineralization of human enamel lesions or cavities and pores in historical artifacts, we aim to increase the mineral content of the precursor solutions. Furthermore, the effect of a multiple-step infiltration will be investigated. A second part of further experiments will be the improvement of the MCTS by changing the production parameters to decrease the layer thickness and the channel sizes as well.

In the future, the possibility to vary the channel size of the MCTS and the surface properties by modification with different SAMs will enable the adaptation of the MCTS, combined with the infiltration setup, to several additional areas of applications, like micro-fissures in steel or high-performance plastics. Therefore, our developed MCTS provides a quantitative tool to observe and explain several important infiltration processes into different pores.

Acknowledgments: The authors thank the Deutsche Forschungsgemeinschaft for the framework of the Collaborative Research Center SFB-1214 "Anisotropic Particles as Building Blocks" and the included "Particle Analysis Center" (project Z1) for the PXRD measurements. We also thank Brigitte Bössenecker, Elana Harbalik, and Kay Hagedorn for their help in PXRD measurements and the calculation of the crystallite sizes. Furthermore, we want to thank Julian Opel for the graphical design of the infiltration setup.

Author Contributions: Helmut Cölfen, Stefan L. P. Wolf, and Dominik Gruber conceived and designed the experiments; Dominik Gruber, Stefan L. P. Wolf, Andra-Lisa M. Hoyt, and Julian P. Konsek performed the experiments and analyzed the data; and Dominik Gruber, Stefan L. P. Wolf, and Helmut Cölfen wrote the paper.

Conflicts of Interest: The authors declare no conflict of interest. 


\section{References}

1. Cölfen, H.; Mann, S. Higher-order organization by mesoscale self-assembly and transformation of hybrid nanostructures. Angew. Chem. Int. Ed. 2003, 42, 2350-2365. [CrossRef] [PubMed]

2. Christenson, K.H. Confinement effects on freezing and melting. J. Phys. Condens. Matter 2001, $13, \mathrm{R} 95$. [CrossRef]

3. Wang, Y.-W.; Christenson, H.K.; Meldrum, F.C. Confinement leads to control over calcium sulfate polymorph. Adv. Funct. Mater. 2013, 23, 5615-5623. [CrossRef]

4. Cantaert, B.; Beniash, E.; Meldrum, F.C. Nanoscale confinement controls the crystallization of calcium phosphate: Relevance to bone formation. Chem. Eur. J. 2013, 19, 14918-14924. [CrossRef] [PubMed]

5. Wolf, S.L.P.; Jahme, K.; Gebauer, D. Synergy of $\mathrm{Mg}^{2+}$ and poly(aspartic acid) in additive-controlled calcium carbonate precipitation. CrystEngComm 2015, 17, 6857-6862. [CrossRef]

6. Kellermeier, M.; Picker, A.; Kempter, A.; Cölfen, H.; Gebauer, D. A straightforward treatment of activity in aqueous $\mathrm{CaCO}_{3}$ solutions and the consequences for nucleation theory. Adv. Mater. 2014, 26, 752-757. [CrossRef] [PubMed]

7. Tester, C.C.; Brock, R.E.; Wu, C.-H.; Krejci, M.R.; Weigand, S.; Joester, D. In vitro synthesis and stabilization of amorphous calcium carbonate (ACC) nanoparticles within liposomes. CrystEngComm 2011, 13, 3975-3978. [CrossRef]

8. Xu, A.-W.; Ma, Y.; Cölfen, H. Biomimetic mineralization. J. Mater. Chem. 2007, 17, 415-449. [CrossRef]

9. Picker, A.; Nicoleau, L.; Nonat, A.; Labbez, C.; Cölfen, H. Identification of binding peptides on calcium silicate hydrate: A novel view on cement additives. Adv. Mater. 2014, 26, 1135-1140. [CrossRef] [PubMed]

10. Kim, Y.-Y.; Hetherington, N.B.J.; Noel, E.H.; Kröger, R.; Charnock, J.M.; Christenson, H.K.; Meldrum, F.C. Capillarity creates single-crystal calcite nanowires from amorphous calcium carbonate. Angew. Chem. Int. Ed. 2011, 50, 12572-12577. [CrossRef] [PubMed]

11. Hamilton, B.D.; Ha, J.-M.; Hillmyer, M.A.; Ward, M.D. Manipulating crystal growth and polymorphism by confinement in nanoscale crystallization chambers. Acc. Chem. Res. 2012, 45, 414-423. [CrossRef] [PubMed]

12. Finnemore, A.S.; Scherer, M.R.J.; Langford, R.; Mahajan, S.; Ludwigs, S.; Meldrum, F.C.; Steiner, U. Nanostructured calcite single crystals with gyroid morphologies. Adv. Mater. 2009, 21, 3928-3932. [CrossRef]

13. Campbell, J.M.; Meldrum, F.C.; Christenson, H.K. Observing the formation of ice and organic crystals in active sites. Proc. Natl. Acad. Sci. USA 2017, 114, 810-815. [CrossRef] [PubMed]

14. Diao, Y.; Myerson, A.S.; Hatton, T.A.; Trout, B.L. Surface design for controlled crystallization: The role of surface chemistry and nanoscale pores in heterogeneous nucleation. Langmuir 2011, 27, 5324-5334. [CrossRef] [PubMed]

15. Ha, J.-M.; Wolf, J.H.; Hillmyer, M.A.; Ward, M.D. Polymorph selectivity under nanoscopic confinement. J. Am. Chem. Soc. 2004, 126, 3382-3383. [CrossRef] [PubMed]

16. Stephens, C.J.; Ladden, S.F.; Meldrum, F.C.; Christenson, H.K. Amorphous calcium carbonate is stabilized in confinement. Adv. Funct. Mater. 2010, 20, 2108-2115. [CrossRef]

17. Stephens, C.J.; Kim, Y.-Y.; Evans, S.D.; Meldrum, F.C.; Christenson, H.K. Early stages of crystallization of calcium carbonate revealed in picoliter droplets. J. Am. Chem. Soc. 2011, 133, 5210-5213. [CrossRef] [PubMed]

18. Wang, Y.-W.; Christenson, H.K.; Meldrum, F.C. Confinement increases the lifetimes of hydroxyapatite precursors. Chem. Mater. 2014, 26, 5830-5838. [CrossRef]

19. Gardeniers, H.J.G.E. Chemistry in nanochannel confinement. Anal. Bioanal. Chem. 2009, 394, 385-397. [CrossRef] [PubMed]

20. Markl, G. Minerale und Gesteine; Springer: Berlin/Heidelberg, Germany, 2015; Volume 3.

21. Fratini, F.; Pecchioni, E.; Cantisani, E.; Rescic, S.; Vettori, S. Pietra serena: The stone of the renaissance. Geol. Soc. Lond. Spec. Publ. 2014, 407. [CrossRef]

22. Baglioni, P.; Chelazzi, D. Nanoscience for the Conservation of Works of Art; RSC Publishing: Cambridge, UK, 2013.

23. Karagiannis, N.; Karoglou, M.; Bakolas, A.; Moropoulou, A. New Approaches to Building Pathology and Durability; Springer: Singapore, 2016.

24. Ambrosi, M.; Dei, L.; Giorgi, R.; Neto, C.; Baglioni, P. Colloidal particles of $\mathrm{Ca}(\mathrm{OH})_{2}$ : Properties and applications to restoration of frescoes. Langmuir 2001, 17, 4251-4255. [CrossRef] 
25. Giorgi, R.; Dei, L.; Baglioni, P. A new method for consolidating wall paintings based on dispersions of lime in alcohol. Stud. Conserv. 2000, 45, 154-161.

26. Otero, J.; Charola, A.E.; Grissom, C.A.; Starinieri, V. An overview of nanolime as a consolidation method for calcareous substrates. Ge-Conservación 2016, 11, 71-78.

27. Kassebaum, N.J.; Bernabé, E.; Dahiya, M.; Bhandari, B.; Murray, C.J.L.; Marcenes, W. Global burden of untreated caries. J. Dent. Res. 2015, 94, 650-658. [CrossRef] [PubMed]

28. Bagramian, R.A.; Garcia-Godoy, F.; Volpe, A.R. The global increase in dental caries. A pending public health crisis. Am. J. Dent. 2009, 22, 3-8. [PubMed]

29. Selwitz, R.H.; Ismail, A.I.; Pitts, N.B. Dental caries. Lancet 2007, 369, 51-59. [CrossRef]

30. Palmer, L.C.; Newcomb, C.J.; Kaltz, S.R.; Spoerke, E.D.; Stupp, S.I. Biomimetic systems for hydroxyapatite mineralization inspired by bone and enamel. Chem. Rev. 2008, 108, 4754-4783. [CrossRef] [PubMed]

31. Dorozhkin, S.V.; Epple, M. Biological and medical significance of calcium phosphates. Angew. Chem. Int. Ed. 2002, 41, 3130-3146. [CrossRef]

32. Ten Cate, J.M. Remineralization of deep enamel dentine caries lesions. Aust. Dent. J. 2008, 53, 281-285. [CrossRef] [PubMed]

33. Ginebra, M.P.; Espanol, M.; Montufar, E.B.; Perez, R.A.; Mestres, G. New processing approaches in calcium phosphate cements and their applications in regenerative medicine. Acta Biomater. 2010, 6, 2863-2873. [CrossRef] [PubMed]

34. Suchanek, W.; Yoshimura, M. Processing and properties of hydroxyapatite-based biomaterials for use as hard tissue replacement implants. J. Mater. Res. 1998, 13, 94-117. [CrossRef]

35. Yamagishi, K.; Onuma, K.; Suzuki, T.; Okada, F.; Tagami, J.; Otsuki, M.; Senawangse, P. Materials chemistry: A synthetic enamel for rapid tooth repair. Nature 2005, 433, 819. [CrossRef] [PubMed]

36. Hannig, M.; Hannig, C. Nanomaterials in preventive dentistry. Nat. Nanotech. 2010, 5, 565-569. [CrossRef] [PubMed]

37. Denry, I.; Kelly, J.R. Emerging ceramic-based materials for dentistry. J. Dent. Res. 2014, 93, 1235-1242. [CrossRef] [PubMed]

38. Li, J.; Xie, X.; Wang, Y.; Yin, W.; Antoun, J.S.; Farella, M.; Mei, L. Long-term remineralizing effect of casein phosphopeptide-amorphous calcium phosphate (CPP-ACP) on early caries lesions in vivo: A systematic review. J. Dent. 2014, 42, 769-777. [CrossRef] [PubMed]

39. Reynolds, E.C. Remineralization of enamel subsurface lesions by casein phosphopeptide-stabilized calcium phosphate solutions. J. Dent. Res. 1997, 76, 1587-1595. [CrossRef] [PubMed]

40. Dei, L.; Mauro, M.; Baglioni, P.; Manganelli Del Fà, C.; Fratini, F. Growth of crystal phases in porous media. Langmuir 1999, 15, 8915-8922. [CrossRef]

41. Freire-Lista, D.M.; Gomez-Villalba, L.S.; Fort, R. Microcracking of granite feldspar during thermal artificial processes. Period Min. 2015, 84, 519-537.

42. Bortz, S.; Stecich, J.; Wonneberger, B.; Chin, I. Accelerated weathering in building stone. Int. J. Rock Mech. Min. Sci. 1993, 30, 1559-1562. [CrossRef]

43. Besinis, A.; De Peralta, T.; Tredwin, C.J.; Handy, R.D. Review of nanomaterials in dentistry: Interactions with the oral microenvironment, clinical applications, hazards, and benefits. ACS Nano 2015, 9, 2255-2289. [CrossRef] [PubMed]

44. Burwell, A.K.; Thula-Mata, T.; Gower, L.B.; Habeliz, S.; Kurylo, M.; Ho, S.P.; Chien, Y.C.; Cheng, J.; Cheng, N.F.; Gansky, S.A.; et al. Functional remineralization of dentin lesions using polymer-induced liquid-precursor process. PLoS ONE 2012, 7, e38852. [CrossRef] [PubMed]

45. Kirkham, J.; Firth, A.; Vernals, D.; Boden, N.; Robinson, C.; Shore, R.C.; Brookes, S.J.; Aggeli, A. Self-assembling peptide scaffolds promote enamel remineralization. J. Dent. Res. 2007, 86, 426-430. [CrossRef] [PubMed]

46. Wolf, S.L.P.; Caballero, L.; Melo, F.; Cölfen, H. Gel-like calcium carbonate precursors observed by in situ AFM. Langmuir 2017, 33, 158-163. [CrossRef] [PubMed]

47. Wang, P.; Yook, S.-W.; Jun, S.-H.; Li, Y.-L.; Kim, M.; Kim, H.-E.; Koh, Y.-H. Synthesis of nanoporous calcium phosphate spheres using poly(acrylic acid) as a structuring unit. Mater. Lett. 2009, 63, 1207-1209. [CrossRef]

48. Bain, C.D.; Troughton, E.B.; Tao, Y.T.; Evall, J.; Whitesides, G.M.; Nuzzo, R.G. Formation of monolayer films by the spontaneous assembly of organic thiols from solution onto gold. J. Am. Chem. Soc. 1989, 111, 321-335. [CrossRef] 
49. Love, J.C.; Estroff, L.A.; Kriebel, J.K.; Nuzzo, R.G.; Whitesides, G.M. Self-assembled monolayers of thiolates on metals as a form of nanotechnology. Chem. Rev. 2005, 105, 1103-1170. [CrossRef] [PubMed]

50. Wu, W.; Nancollas, G.H. The relationship between surface free-energy and kinetics in the mineralization and demineralization of dental hard tissue. Adv. Dent. Res. 1997, 11, 566-575. [CrossRef] [PubMed]

51. De Jong, H.P.; van Pelt, A.W.J.; Arends, J. Contact angle measurements on human enamel—An in vitro study of influence of pellicle and storage period. J. Dent. Res. 1982, 61, 11-13. [CrossRef] [PubMed]

52. Huang, S.-C.; Naka, K.; Chujo, Y. A carbonate controlled-addition method for amorphous calcium carbonate spheres stabilized by poly(acrylic acid)s. Langmuir 2007, 23, 12086-12095. [CrossRef] [PubMed]

53. Drouet, C. Apatite formation: Why it may not work as planned, and how to conclusively identify apatite compounds. BioMed Res. Int. 2013, 2013, 12. [CrossRef] [PubMed]

54. Scherrer, P. Bestimmung der größe und der inneren struktur von kolloidteilchen mittels röntgenstrahlen. Nachr. Ges. Wiss. Gött. Math.-Phys. Kl. 1918, 2, 98.

(c) 2017 by the authors. Licensee MDPI, Basel, Switzerland. This article is an open access article distributed under the terms and conditions of the Creative Commons Attribution (CC BY) license (http:/ / creativecommons.org/licenses/by/4.0/). 